\title{
English Language Proficiency and Immigrant Families Annual Earnings and Medical Care Spending in the USA
}

\author{
Ibrahim Niankara \\ College of Business Administration, Al Ain University of Science and Technology, P.O. Box: \\ 112612, Abu Dhabi Campus, United Arab Emirates, Tel: (+971)24444696 \\ Ext: 539; Email: Ibrahim.niankara@aau.ac.ae
}

\begin{abstract}
This paper investigates the role of English language proficiency (ELP) as a measure of cultural integration on U.S. immigrant families' economic integration, as measured by annual earnings, and health care market integration, as captured by annual medical care spending. Bayesian Markov Chain Monte Carlo (MCMC) estimation of a mixed bivariate ordered probit (MBOP) model of annual earnings and medical care spending is conducted using a nationally representative pooled cross-sectional sample data from the U.S. National Health Interview Surveys (NHIS). The results reveal that limited English proficiency is associated with lower marginal earnings propensities $(-\$ 44.83,-\$ 50.66$, and $-\$ 56.97)$, and higher marginal medical care spending propensities $(\$ 8.09, \$ 6.09$, and $\$ 4.32)$ for each of the three decreasing levels of ELP. Furthermore, we find a small yet statistically significant positive $7.2 \%$ correlation between immigrant families' annual earnings and medical care spending propensities. Therefore investing to raise immigrants' families ELP in the U.S. would not only contribute to more effective socio-economic integration, but also strengthen the U.S. workforce and economy for decades to come.
\end{abstract}

JEL classification: I12, I31, J15, J31, J61, F22, Z13

Key words: English proficiency, Earnings, Immigrants, MCMC, Medical Care Spending 


\section{Introduction}

According to the UN's International Organization, for Migration (IOM) the world is faces the highest levels of forced displacement recorded since World War II, with a dramatic increase in the number of refugees, asylum seekers and internally displaced people across various regions of the world. There are an estimated 244 million international migrants $(3.3 \%$ of the world's population), an increase from 155 million in 2000 (The Lancet Public Health, 2018). As a response, on May 17-19, 2018 over 700 participants from 50 countries met and signed as "The Edinburgh Declaration (ED) ${ }^{1}$ " during the first World Congress on Migration, Ethnicity, Race and Health. The landmark global consensus reached by the signees of the ED establishes a commitment to respond to the challenges and opportunities that migration and diversity presents for health and well-being. Although characterized by global commitments, including the 2030 Agenda for Sustainable Development, the second 15 years cycle of the 21st century is expected to experience a growing wave of electoral support for nationalism and populism ${ }^{2}$, especially in regards to immigration. Whether past trends in immigrants' socio-economic integration in most developed host nations will continue is unclear (Batalova et al., 2018; Pierce et al., 2018).

In the U.S. for example, immigrants ${ }^{3}$, also referred to as "foreign born," make up a large and increasing share of the population. In 2015, U.S. Census Bureau estimates an immigrant population of approximately 43.3 million, which is 13.5 percent of the total population of 321.4 million. Immigrants to the U.S. come from more than 100 different countries (Camarota, 2012). The majority of recent migrants come from Latin America and Asia, The top ten countries of

\footnotetext{
${ }^{1}$ For more information, see http://www.merhcongress.com/welcome/edinburgh-declaration/.

${ }^{2}$ Although the policies vary from country to country, they all share a number of characteristics: a sense of exclusive nationalism, belief that national identity is under threat from foreign cultures, desire to sharply cut immigration, and distrust of elites (Shain, 2018).

${ }^{3}$ Defined by the U.S. Census Bureau as individuals who do not have U.S. citizenship at birth, including naturalized citizens, lawful permanent residents, certain legal nonimmigrants (e.g., individuals on student or work visas), those admitted under refugee or asylum status, and individuals illegally residing in the United States and their native born child (2nd generation).
} 
origin account for $60 \%$ of U.S. immigration ${ }^{4}$. With U.S. fertility rates at a historic low, the Census Bureau projects that net international migration will be the main driver of U.S. population growth between 2027 and 2038 (Batalova and Alperin, 2018).

Present-day immigration in the U.S. is further characterized by a greater variation in immigrants' geographic distribution across the country, and a greater diversity with regard to their formal immigration status (Kandell, 2011). In 1990, 73\% of immigrants resided in the traditional gateway states, compared to $27 \%$ living in all other states. By 2014, the proportion living in traditional gateway states declined to $64 \%$, compared to $36 \%$ of immigrants living in nontraditional immigration states (Camarota and Zeigler, 2016). As shown in figure (1), U.S. immigrant population grew by $15 \%$ or more in 15 states, with an overall national average of 9\% (Batalova and Alperin, 2018).

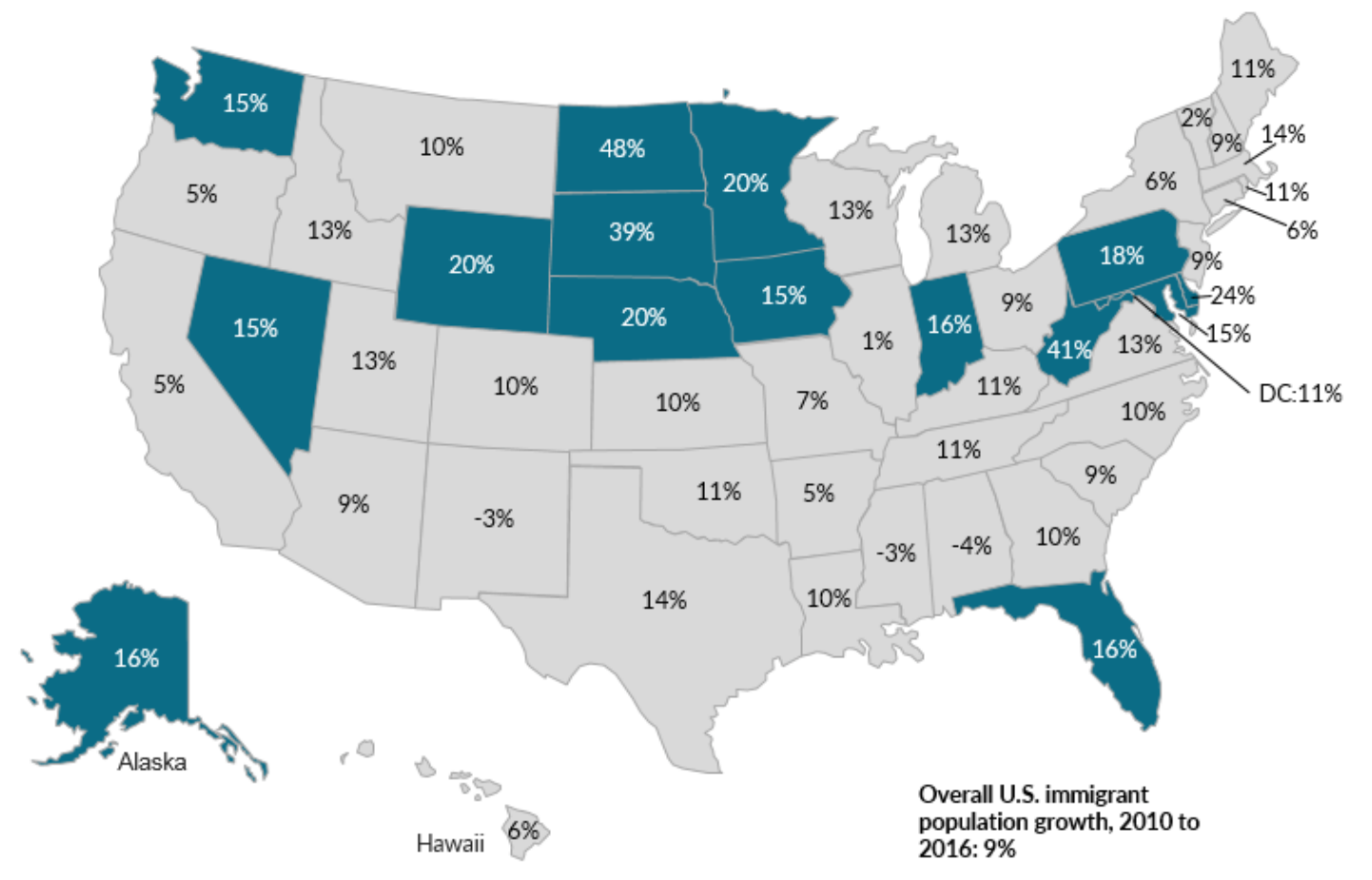

Figure 1: Percentage change in immigrant population by States 2010-2016

(Source: Migration Policy Institute (MPI) using U.S. Census Bureau data from the 2010 and 2016 from the American Community Survey).

\footnotetext{
${ }^{4}$ Mexico (26.9 \%), India (5.5\%), China (4.8 \%) and Philippines (4.6\%), El Salvador (3.1\%), Vietnam (3.0 percent), Cuba (2.8 percent), and Korea (2.4 percent), as well as the Dominican Republic (2.5 percent) and Guatemala (2.1 percent).
} 
Despite this diversity, U.S. immigrants experience an assimilation process through which they learn and adapt to U.S. laws, norms, values, and language (Borjas, 2007). In addition to immigrant well-being, various economic impacts of assimilation have received attention from scholars and policy makers, including immigrant effects on fiscal health of the jurisdictions in which they reside and on direct effects on the native workforce (Terrazas, 2011; Shain, 2018). Economists have relied on a narrower definition than scholars from other fields based on earnings and wages (Xie and Gough, 2011). This concept has also been extended to include a disparity in welfare use (Xu and Kalina, 2012), where welfare utilization may indicate the extent of immigrants' economic hardships.

The labor market has been the most important institution for the economic and social integration of immigrants in the U.S. (Terrazas, 2011), where employment is used as a primary indicator (Camarota, 2012; Capps et al., 2013). Recent national estimates (Camarota and Zeigler, 2016) suggest that contemporary immigrants are well integrated into the U.S. labor market, compared to past immigrants and immigrants to other developed countries. Looking at job quality however, this later study found that immigrants are mainly concentrated in lower skilled service and industrial occupations, compared to their native counterparts. Accordingly, immigrants have relatively lower earnings. In 2015 for example, the per-capita median household income of immigrant-headed households $(\$ 16,025)$, lagged behind that of nativeheaded households (\$22,941) (Current Population Survey; ASEC Supplement, 2015). In 2016, about $16 \%$ of immigrant families had an annual income below the federal poverty line, compared to 12-14 percent among the U.S. born (Batalova et al., 2018), suggesting that members of immigrant households are more vulnerable to economic hardship.

Because of this vulnerability, immigrant families are relatively more likely than their native counterparts to live in poverty and rely on welfare programs. For example, in examining an extensive list of welfare programs, including Temporary Assistance to Needy Families 
(TANF), state administered general assistance (GA), Supplemental Security Income (SSI), Supplemental Nutrition Assistance Program (SNAP), free and subsidized school lunch, Women, Infants, and Children nutrition program (WIC), subsidized and government-owned housing, and Medicaid, Camarota and Zeigler (2016) showed that current immigrants are more likely to use public assistance than natives.

As laws are drafted limiting illegal immigrants access to public programs (Batalova et al., 2018), these families will likely be more vulnerable and at elevated risk for other social problems (Castañeda et al., 2015). This may affect or be affected by their unsuccessful economic integration. Indeed Pierce et al. (2018) reports a significant behavioral adjustment in the U.S. immigrants' population including a sharp decrease in crime reporting (e.g. domestic violence); fewer applications for public benefits to which immigrants and their U.S.-born children are entitled; and rising no-shows at health care appointments. The consequences of which include poor physical health (heart disease, high blood pressure, diabetes) (Blanas et al., 2013 ; Carten et al., 2013 ; Hoffman et al., 2011), and elevated risk of mental health problems including depression and anxiety (Batalova et al.,2018; Chung, 2012; Jurcik et al., 2013; Leung et al., 2012).

Among the most important factors, affecting immigrants' households' vulnerability to health and labor market hardship is the lack of "country specific human capital" such as English language proficiency $\left(\right.$ ELP) ${ }^{5}$ for new settlers (Divi et al., 2007; Kim et al., 2011). In fact, ELP could affect immigrants' health and labor market outcomes through several potential channels (Sentell and Braun, 2012). Theoretically, Grossman's (1972) model of health production identifies a twofold role of language skills: it directly affects the efficiency of health production and indirectly affects access to health inputs. The empirical evidence in several parts of world

\footnotetext{
${ }^{5}$ Limited ELP refers to those who reported speaking English "not at all," "not well," or "well" on the questionnaire. Individuals who reported speaking English exclusively or "very well" are considered proficient in English.
} 
also suggests that proficiency in the primary spoken language in the location in which one lives improves one's earnings potential through favorable employment outcomes, resulting in more investment in one's health (Duncan and Mavisakalyan 2015) in Russia, (Chiswick and Miller, 2010) in the U.S., and (Guven \& Islam, 2015; Clarke and Isphording, 2017) in Australia. In a more comprehensive report, Chiswick and Miller (2015) also arrive at the same conclusion for immigrants in the U.S., Canada, Australia, the UK, Germany, Israel and Spain.

Although the theoretical and empirical evidence support a significant relationship between health and labor market outcomes, the existing literature is silent about the impact of language proficiency on the joint outcomes of immigrants' labor market earnings and health care spending in the U.S. One stream of literature focuses on how language proficiency affects health care market outcomes (Dillender, 2017; Fernandez et al. 2011; Fryer et al., 2013; Jacobs, 2016; Lebrun et al., 2012; López et al., 2015; Schachter et al. 2012; Schwei et al., 2018; Tegegne, 2018; Zendedel et al., 2018).

The other stream examines its effect on labor market outcomes (Bleakley and Chin, 2010; Budria and Swedberg, 2015; Gentsch and Massey, 2011; Miranda and Zhu, 2013; Schuss, 2018). This study, which follows Shields and Price (2002), Chiswick and Miller (2010), and Elsayed and DeGrip (2018), brings these two aspects of immigrants' integration together, and describes the welfare implications of immigrants English language proficiency in the U.S. More specifically, it introduces the concept of "immigrants' health-economic integration", and investigates the health care market and labor market outcomes of immigrants with various levels of English language proficiency. The general question it seeks to address is:

\footnotetext{
${ }^{6}$ Immigrants health-economic integration/inclusion can be described as a policy goal for governments, directed at eliminating the exclusion of all immigrants to enable everyone (immigrants and native alike) "to have access to, use, participate in, benefit from and feel a sense of belonging to both the health care market and the labor market of the host country".
} 
How does English language proficiency affect immigrant families' health care market and labor market integration in post-ACA- USA?

More specifically,

(i) Q1: How does English language proficiency affect immigrant families' annual earnings and Medical care spending in post-ACA- USA?

(ii) Q2: What relationship exists between immigrant families' annual earnings and medical care spending in post-ACA-USA?

Based on the above-discussed theoretical and empirical evidence, we formulate the following hypothesis in relation to our two specific questions

(i) H01: English language proficiency increases immigrant families' earnings in postACA-USA [see figure (2) arrow (1)]

(ii) H02: English language proficiency reduces immigrant families' medical care spending in post-ACA-USA [see figure (2) arrow (2)]

(iii) H03: There is a significant positive relationship between immigrant families' annual earnings and medical care spending in post-ACA-USA [see figure (2) arrow (3)]

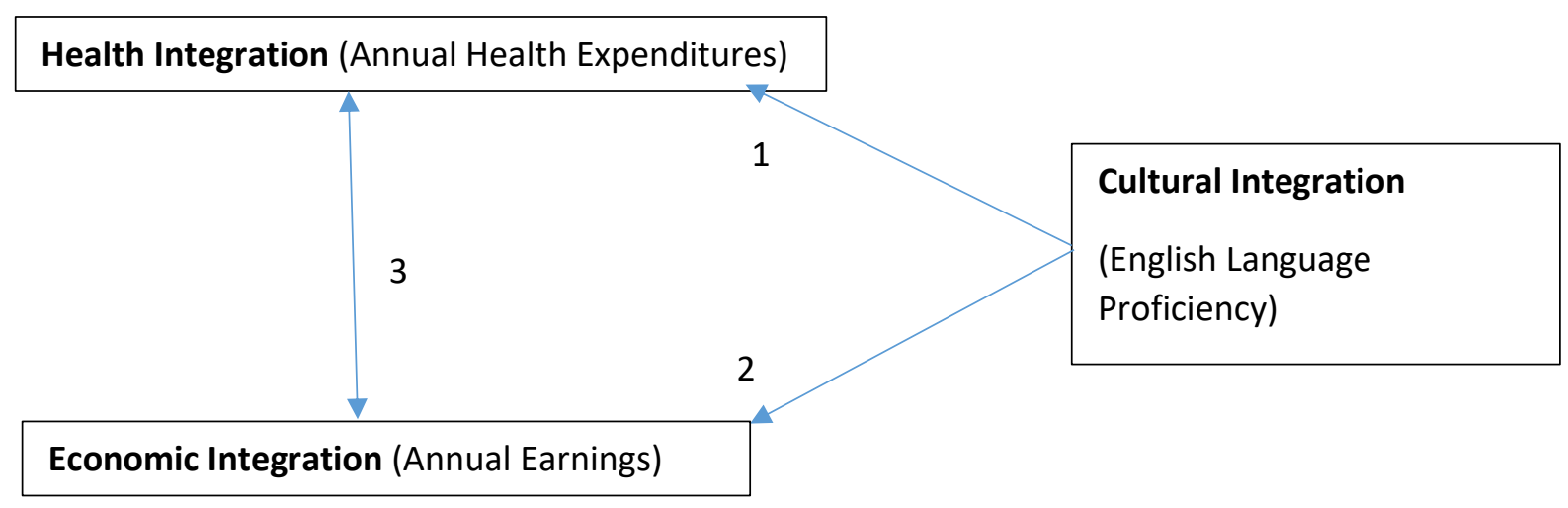

Figure 2: The Conceptual Framework of the effect of ELP on Health-Economic Integration 
In order to test the above hypotheses and provide answers to the raised questions, we rely on a Generalized Linear Mixed Modelling of the Bivariate ordered Probit model of Earnings and Medical Expenditure, which is then estimated Using Bayesian Markov Chain Monte Carlo Methods.

In doing so, the contribution of this paper is two folds:

- It provides the most up to date treatment of the topic using a nationally representative sample of the U.S. immigrant population

- Methodological: through the joint bivariate representation of the integration process, and subsequent use of MCMC methods for parameter identification.

The rest of the paper is organized as follows. Section 2 reviews the literature on language proficiency and immigrants' welfare as measured by health and labor market outcomes. Section 3 describes the methodology followed to test the hypothesis. Section 4 presents and discusses the findings, while section 6 concludes the analysis and provide recommendations.

\section{Literature review}

Our review of the literature on language proficiency and immigrant welfare is organized in two main streams: (i) language proficiency and immigrant health care market integration, and (ii) language proficiency and immigrant labor market integration. Before reviewing these two streams of literature, the concept of immigrants' integration is discussed.

\subsection{Concept(s) of immigrants integration}

The concept of integration, in its usage pertaining to immigration, is open to a range of definitions, which undergo particularly significant variations between different national contexts (Rudiger and Spencer, 2003). In the broadest sense, integration means the process by which people who are relatively new to a country become part of society (Duman, 2018). In 
view of a tendency to conceive integration as a one-way assimilation, this concept is being replaced with other terms such as "inclusion," which has the advantage of providing a better link to policy concerns, since policymakers use it to refer to all social groups, not just immigrants (Kogan et al., 2018). The debates around the usage of the term "integration" indicate that it is a highly normative concept. As a policy objective, integration implies an assumption about a desirable social order, with a high degree of internal cohesion, making it attractive to policymakers, who aim for stability (Elsayed and De Grip, 2018).

If integration is measured in relation to an existing social order with its hegemonic practices and values, then its focus will always be on immigrants' adaptation rather than steps that may be necessary to facilitate their inclusion and participation (Rudiger and Spencer, 2003). This means that immigrants' integration failure can be the result of a resistance to change on part of the host society. This could further mean for example that an immigrant can be excluded from receiving preventive health care, or accessing employment, because health services are only provided, or employment tasks are only performed in the main national language (English) (Bousmah et al., 2018). While it is crucial that immigrants take an active role in the integration process, this is only possible when existing structures are not so rigid to allow it (Duman, 2018). In pluralist democracies, such change should not be perceived as a threat to stability but as part of the flexibility and openness of the society, which is constantly developing, striving for greater equality and more opportunities for all members (Elsayed and De Grip, 2018). In such context, immigrants' health-economic integration/inclusion can be described as a policy goal for governments, to eliminate immigrants' exclusions from the health care market and the labor market of the host country.

\subsection{Language proficiency and immigrants' health care market integration}

Jacobs, et al. (2006) stressed the need for more research on language barriers in health care. Since this seminal paper, many others have pursued this agenda (e.g., Dillender, 2017; 
Fryer et al., 2013; Jacobs, 2016; López et al., 2015; Schwei et al., 2018). For example Mui et al. (2007), and Gee and Ponce (2010) found that English Language Proficiency (ELP) has a direct impact on health related quality of life. ELP is also reported to enhance immigrants' health status, access to primary and preventive health care (Salinas and Sheffield, 2011), enrollment in health insurance programs (Lebrun 2012; Schachter et al. 2012; Dillender, 2017), adherence with medical advice (Andreae et al., 2016) and satisfaction with medical treatment (Fernandez et al. 2011). U.S. Immigrants with limited ELP tend to have a poorer understanding of their illness, lack understanding of the treatment that they receive (González et al. 2010; Wilson et al., 2005) and are less likely to follow treatment instructions and physician's recommendations or to pay follow-up health visits (Clark et al. 2004). Limited ELP inhibits both patients' ability to accurately express symptoms and physicians' ability to diagnose (Divi et al. 2007). Thus, immigrants with limited ELP are more likely to rely on interpreters (Fryer et al., 2013; Schwei et al., 2018), which sometimes occurs in an informal setting (Zendedel et al., 2018), with potential misinterpretations (Nápoles et al., 2015; Squires and Jacobs, 2016), leading to unnecessary diagnostic testing and hospital admissions (John-Baptiste et al. 2004), increased risk of inappropriate treatment and potential for misdiagnosis (Cheng et al., 2007; López et al., 2015).

\subsection{Language proficiency and immigrants labor market integration}

Theoretically, much of the empirical economic literature on language proficiency and immigrants' labor market outcomes have relied on human capital theory (Becker, 1962). In this context, the concept of human capital has been used to describe the language skills and experiences that may help immigrants' economic integration (including labor market participation and earning) (Bishop, 1994; Borjas, 2005; Budria and Swedberg, 2015). For example, Chiswick and Miller (2015) shows that immigrants have a weaker economic position at arrival than that of their native counterparts. Mainly because of low "country specific" human 
capital (Miranda and Zhu, 2013), including English language proficiency (Funkhouser, 2000; Schuss, 2018). According to Sanders and Nee (1996), increased ELP helps an immigrant access information and social contacts, allowing one to build more cultural knowledge, and adjust more easily to the new host country labor market. For example, Bates (1994) found that Asian immigrant-owned small businesses have more success due to owners' investment in human capital including ELP, which Chiswick and Miller (2015) believes is a form of host country specific human capital that may improve one's economic integration in terms of employment and/or higher wages. This assumption has been supported in earlier studies on the impact of immigrants' ELP on earnings (Bleakley and Chin, 2010; Kossoudji, 1988), and further confirmed by Chiswick and Miller (2010). Moreover, Shield and Price (2002), Pfeffer and Parra (2009), and Gentsch and Massey, (2011) also found increased ELP to improve employment conditions and job tenure for Mexican immigrant workers.

\section{Methodology}

The theoretical (Becker, 1962; Grossman, 1972) and empirical (Brunello et al. 2016) bidirectional relationship between labor market and health care market outcomes. Therefore, a model of how ELP affects health care must take into account the endogeneity of annual earnings. Ignoring this endogeneity biases the estimated effects of language proficiency and other relevant covariates including annual earnings.

Several methods could be used to accommodate this type of endogeneity, including instrumental variable methods (Angrist et al., 1996) and endogenous switching regressions (Lee and Porter, 1984). Due to the difficulty associated with finding suitable instruments (Bound et al., 1995), and the qualitative ordinal nature of our measured health care market (annual expenditures) and labor market (annual earnings) outcomes, we rely on the switching regression framework following (Lee and Porter, 1984, Niankara, 2018b). Doing so requires the process generating the observed annual earnings to be jointly modelled with the process generating the 
observed annual health expenditures, while looking at the causal influence of English language proficiency on both. This representation allows the error terms from these two processes to correlate thereby resolving the observed endogeneity issue (Niankara, 2016). Since both annual earnings and annual medical expenditures are measured on a qualitative ordinal scale, the resulting model will be bivariate ordered as described next.

\subsection{The Bivariate Ordered Probit (BOP)}

We rely on a generalized linear mixed model representation of the BOP. For this we define $\mathrm{H}_{i}$ : The observed health care market outcome for respondent $i$ (Family medical expenditures) $\mathrm{L}_{i}$ : The observed labor market outcome for respondent $i$ (Family earnings) $H_{i}^{*}$ : The latent propensity to spend on medical care annually for respondent $i$ family $L_{i}^{*}$ : The latent propensity to earn annually for respondent $i$ family

Following Sajaia's (2008) BOP model representation, we assume that an immigrant family latent propensity to earn annually $L_{i}^{*}$ and latent propensity to spend on medical care annually $H_{i}^{*}$ are determined by the following system of linear equations:

$$
\begin{aligned}
L_{i}^{*} & =X_{1 i}^{\prime} \beta_{1}+Z_{1 i}^{\prime} u_{1}+\epsilon_{1 i} \\
H_{i}^{*} & =X_{2 i}^{\prime} \beta_{2}+Z_{2 i}^{\prime} u_{2}+\epsilon_{2 i}
\end{aligned}
$$

Where $X_{1 i}^{\prime}$ and $X_{2 i}^{\prime}$ represent the fixed effects vectors of explanatory variables in each equation respectively, and include our primary variable of interest, English language proficiency (ENGLANG2), along with health (HICOSTR2, PHSTAT2, FSA2, ExtendCov2, MEDBPAY), socio-demographic (AGE_P, EDUC1, MaritStat, SEX, CITIZENP) and economic control factors (WRKHRS2). $\beta_{1}$ and $\beta_{2}$ are the corresponding vectors of unknown fixed effects to be estimated. $Z_{1 i}^{\prime}$ and $Z_{2 i}^{\prime}$ represent the random effects vectors of explanatory variables in each equation respectively, and include the indicators of regional variations (REGION2), and annual 
variations (SURVY_R) in U.S. immigrant families annual earnings and medical care spending propensities. $u_{1}$ and $u_{2}$ are the corresponding unknown random effects to be estimated. $\epsilon_{1 i}$ and $\epsilon_{2 i}$ are the error terms of the system, and $i$ denotes the individual respondent's subscript. Conditional on $Z_{1 i}^{\prime}$ and $Z_{2 i}^{\prime}$ the fixed effects are assumed to be exogenous, that is

$E\left(X_{1 i}^{\prime} \epsilon_{1 i} \mid Z_{1 i}^{\prime}\right)=E\left(X_{2 i}^{\prime} \epsilon_{2 i} \mid Z_{2 i}^{\prime}\right)=0$

The observed family annual earning $\mathrm{L}_{i}$ and medical care spending $\mathrm{H}_{i}$ are related to the corresponding latent propensities to earn $L_{i}^{*}$ and spend on medical care $H_{i}^{*}$ as follows:

$$
\begin{aligned}
& \mathrm{L}_{i}=\left\{\begin{array}{llr}
1 \text { or }[\$ 0-\$ 34,99] & \text { if } & L_{i}^{*} \leq \mu_{1} \\
2 \text { or }[\$ 35,000-\$ 64,999] & \text { if } \quad \mu_{1} \leq \quad L_{i}^{*} \leq \mu_{2} \\
3 \text { or }[\$ 65000 \text { and more }] & \text { if } \quad \mu_{2}<L_{i}^{*}
\end{array}\right.
\end{aligned}
$$

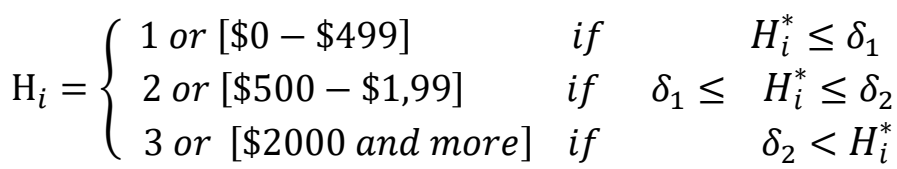

Where the unknown cut-offs satisfy the condition that $\mu_{1}<\mu_{2}$ and $\delta_{1}<\delta_{2}$. For identification purposes, the first threshold values are "anchored" a priori, such that $\mu_{1}=\delta_{1}=0$. Following McKelvey and Zavoina (1975) recommendations, we also set $\mu_{0}=\delta_{0}=-\infty$ and $\mu_{3}=\delta_{3}=+\infty$ in order to avoid handling boundary cases separately. As such, the probability of $\mathrm{L}_{i}=\mathrm{j}$ and $\mathrm{H}_{i}=\mathrm{k}$ is:

$$
\begin{aligned}
\operatorname{Pr}\left(\mathrm{L}_{i}=\mathrm{j}, \mathrm{H}_{i}=\mathrm{k}\right)= & \operatorname{Pr}\left(\mu_{j-1} \leq L_{i}^{*} \leq \mu_{j}, \delta_{k-1} \leq H_{i}^{*} \leq \delta_{k}\right) \\
& =\operatorname{Pr}\left(L_{i}^{*} \leq \mu_{j}, H_{i}^{*} \leq \delta_{k}\right) \\
& -\operatorname{Pr}\left(L_{i}^{*} \leq \mu_{j-1}, H_{i}^{*} \leq \delta_{k}\right) \\
& -\operatorname{Pr}\left(L_{i}^{*} \leq \mu_{j}, H_{i}^{*} \leq \delta_{k-1}\right) \\
& +\operatorname{Pr}\left(L_{i}^{*} \leq \mu_{j-1}, H_{i}^{*} \leq \delta_{k-1}\right)
\end{aligned}
$$

If we assume $\epsilon_{1 i}$ and $\epsilon_{2 i}$ to have a joint bivariate normal distribution, with correlation $\rho$ then the individual contribution of a respondent $i$ to the likelihood function can be expressed as: 


$$
\begin{aligned}
\operatorname{Pr}\left(\mathrm{L}_{i}=\mathrm{j}, \mathrm{H}_{i}=\mathrm{k}\right) & =\Phi_{2}\left(\mu_{j}-X_{1 i}^{\prime} \beta_{1}-Z_{1 i}^{\prime} u_{1},\left(\delta_{k}-X_{2 i}^{\prime} \beta_{2}-Z_{2 i}^{\prime} u_{2}\right) \zeta, \tilde{\rho}\right) \\
& -\Phi_{2}\left(\mu_{j-1}-X_{1 i}^{\prime} \beta_{1}-Z_{1 i}^{\prime} u_{1},\left(\delta_{k}-X_{2 i}^{\prime} \beta_{2}-Z_{2 i}^{\prime} u_{2}\right) \zeta, \tilde{\rho}\right) \\
& -\Phi_{2}\left(\mu_{j}-X_{1 i}^{\prime} \beta_{1}-Z_{1 i}^{\prime} u_{1},\left(\delta_{k-1}-X_{2 i}^{\prime} \beta_{2}-Z_{2 i}^{\prime} u_{2}\right) \zeta, \tilde{\rho}\right) \\
& +\Phi_{2}\left(\mu_{j-1}-X_{1 i}^{\prime} \beta_{1}-Z_{1 i}^{\prime} u_{1},\left(\delta_{k-1}-X_{2 i}^{\prime} \beta_{2}-Z_{2 i}^{\prime} u_{2}\right) \zeta, \tilde{\rho}\right)
\end{aligned}
$$

Where $\Phi_{2}$ is the bivariate standard normal cumulative distribution, $\zeta=\frac{1}{\sqrt{1+2 \gamma \rho+\gamma^{2}}}$ and $\tilde{\rho}=$ $\zeta(\gamma+\rho)$. Next, we describe the estimation strategy used to uncover the parameters of the model.

\subsection{Estimation Strategies}

Estimation of the above-described generalized linear representation of the bivariate ordered probit model can be done using maximum simulated likelihood methods (Lee, 1992) or Bayesian Markov Chain Monte Carlo (MCMC) methods (Zhao et al., 2006). Because of the multidimensionality of the choice probabilities, and the intractability in integrating over the random effects (McCulloch and Searle, 2001), we employ a Bayesian MCMC methods following (Browne and Draper, 2006; Niankara 2018a)

\subsubsection{The Bayesian MCMC framework}

Because the bivariate ordered probit (BOP) model as represented in equation (1) is a special case of the more general class of Generalized Linear Mixed Models (GLMMs) with a specified probit link function for each outcome variable, we follow the standard multivariate notation for GLMMs (Hadfield, 2010). This is obtained by stacking the vectors of immigrant families' latent propensities to earn $L_{i}^{*}$ and spend on medical care $H_{i}^{*}$ into a single column vector across all $\mathrm{N}$ responding families in the sample. In this form, we obtain a $(2) \times(N)$ dimensional latent vector $\left(\mathbf{Y}^{*}=\left[L_{i}^{*}, H_{i}^{*}\right]\right)$ for the whole sample of respondents:

$$
\mathbf{Y}^{*}=\boldsymbol{X} \boldsymbol{\beta}+\mathbf{Z u}+\boldsymbol{e}
$$


Where $\mathbf{X}$ is a design matrix relating the fixed predictors to the data, and $\boldsymbol{Z}$ is a design matrix relating random predictors to the data. These predictors have associated parameter vector $\boldsymbol{\beta} \sim \boldsymbol{N}\left(\boldsymbol{\beta}_{\mathbf{0}}, \boldsymbol{B}\right)$, and $\boldsymbol{u} \sim \boldsymbol{N}(\mathbf{0}, \boldsymbol{G})$. The residuals vector is represented by $\boldsymbol{e} \sim$ $\boldsymbol{N}(\mathbf{0}, \boldsymbol{R})$. In this formulation $\boldsymbol{B}, \boldsymbol{G}$ and $\boldsymbol{R}$ are the expected (co)variance matrices of the fixed effects, random effects and residuals, respectively. They are typically unknown, and must be estimated from the data. Since no distinction is made between fixed and random effects in a Bayesian analysis, as all effects are considered random, we can combine the design matrices $(\boldsymbol{W}=[\boldsymbol{X}, \boldsymbol{Z}])$ and the parameters $\left(\boldsymbol{\theta}=\left[\boldsymbol{\beta}^{\prime}, \boldsymbol{u}^{\prime}\right]\right)$, to rewrite equation (6) as

$$
\mathbf{Y}^{*}=\boldsymbol{W} \boldsymbol{\theta}+\boldsymbol{e}
$$

The prior distribution for the location effects $\boldsymbol{\theta}$ is multivariate normal, with the zero off diagonal implying a priory independence between fixed effects and random effects

$$
\boldsymbol{\theta}=\left[\begin{array}{l}
\boldsymbol{\beta} \\
\boldsymbol{u}
\end{array}\right] \sim N\left(\left[\begin{array}{c}
\boldsymbol{\beta}_{\mathbf{0}} \\
\mathbf{0}
\end{array}\right],\left[\begin{array}{ll}
\boldsymbol{B} & \mathbf{0} \\
\mathbf{0} & \boldsymbol{G}
\end{array}\right]\right)
$$

The goal of the analysis is to estimate $\boldsymbol{\theta}$. The prior for $\boldsymbol{\theta}$ can be Gibbs sampled in a single block using the method of Gracia-Cortes and Sorensen (2001) as explained below. With conjugate priors, the variance structures $(\mathbf{R}$ and $\mathbf{G})$ follow an inverse-Wishart distribution, which is also Gibbs sampled in a single block. The explicit representation of the $\mathbf{G}$ structure is as follows:

$$
G=\left[\begin{array}{cc}
V_{1} \otimes A_{1} & 0 \\
0 & V_{2} \otimes A_{2}
\end{array}\right]
$$

Where the zeros off diagonal represent the independence between component terms, and $(\otimes)$ is the Kronecker product allowing for the dependence between random effects within each component term. $\mathbf{V}_{\mathbf{1}} \otimes \mathbf{A}_{\mathbf{1}}$ is the expected (co)variance matrix capturing the variations in the measurements of the two outcomes (Earnings, Medical care spending) across the four U.S. census regions, while $\mathbf{V}_{\mathbf{2}} \otimes \mathbf{A}_{\mathbf{2}}$ is the expected (co)variance matrix capturing the variations in 
the measurements of Earnings and medical care spending across the three survey years. The (co)variance matrices $(\mathbf{V})$ are low dimensional and estimated, while the structured matrices (A) are high dimensional and treated as known. The effects of the independent random components are additive $(\oplus)$, such that equation (9) is equivalently represented as:

$$
G=\left(V_{1} \otimes A_{1}\right) \oplus\left(V_{2} \otimes A_{2}\right)
$$

Accounting for these two sources of systematic random variations (regional, and annual) in the measurements of the two outcomes, all remaining variations in earnings and medical care spending are assumed to be idiosyncratic, and thus captured by the residual (co)variance $\boldsymbol{R}$.

\subsubsection{Updating the latent utilities}

For a given individual, the conditional density of the multidimensional latent vector $Y_{i}^{*}$ is given by:

$$
P\left(Y_{i}^{*} \mid \boldsymbol{y}, \boldsymbol{\theta}, \boldsymbol{R}, \boldsymbol{G}\right) \alpha f_{i}\left(y_{i} \mid Y_{i}^{*}\right) f_{N}\left(e_{i} \mid \boldsymbol{r}_{i} \boldsymbol{R}_{/ i}^{-1} \boldsymbol{e}_{/ i}, r_{i}-\boldsymbol{r}_{i} \boldsymbol{R}_{/ i}^{-1} \boldsymbol{r}_{i}^{\prime}\right)
$$

Where $f_{N}$ represents the multivariate normal distribution with specified mean vector and (co)variance matrix. Hence, equation (11) suggests that the conditional density of the latent vector for individual $i$ is proportional to the product of the conditional distribution of the joint outcome $y_{i}$ given the latent vector $Y_{i}^{*}$, and the joint probability density of the utility residuals. The multidimensional vector of residuals $e_{i}$ for individual $i$ follows a conditional normal distribution, where the conditioning is on the residuals associated with the other $(\mathrm{N}-1)$ individuals in the sample. The notation /i denotes vectors or matrices with the $\mathrm{i}^{\text {th }}$ row and or column removed. This conditioning accounts for residual correlation across individuals. Latent propensities are updated in blocks of correlated residuals. This is achieved through block sampling, where a block is a group of residuals expected to be correlated in equation (7), such that equation (11) can be rewritten as:

$$
P\left(y_{k}^{*} \mid \boldsymbol{y}, \boldsymbol{\theta}, \boldsymbol{R}, \boldsymbol{G}\right) \propto p_{i}\left(y_{i} \mid y_{k}^{*}\right) f_{N}\left(\boldsymbol{e}_{\boldsymbol{k}} \mid \mathbf{0}, \boldsymbol{e}_{\boldsymbol{k}}\right)
$$


Where $k$ indexes a block of correlated latent earnings and medical care spending propensities, which have non-zero residual covariance. Because residuals are correlated across outcomes and individuals, we have a total of $(N) \times(2)$ residual correlations, with $k=1$. Therefore the conditional density of each latent propensity $y_{i t}^{*}$ for all $=1$. $\cdots N$, and $t=1,2$ is obtained by conditioning each $e_{i t}$ on the remaining $[1+(N-$ 1) $\times 2$ ] residuals.

Following Haario et al. (2001), the average posterior (co)variance matrix $\mathbf{M}$ of the single block $(2) \times(N)$ dimensional vector $y_{k}^{*}$ with $k=1$ is updated at each iteration of the burn-in. An efficient multivariate proposal density with covariance matrix $v \mathbf{M}$ is determined using adaptive methods during the burn-in phase. The scalar $v$ is obtained using the method of Ovaskainen et al. (2008) so that the proportion of successful jumps in the Markov Chain is optimal at a rate of 0.23 (Gelman et al., 2004).

\subsubsection{Updating the location vector}

The location vector $\left(\boldsymbol{\theta}=\left[\boldsymbol{\beta}^{\prime}, \boldsymbol{u}^{\prime}\right]\right)$ is sampled as a block using a method by GraciaCortes and Sorensen (2001) which involves solving the sparse linear system:

$$
\widetilde{\boldsymbol{\theta}}=\boldsymbol{C}^{-1} \boldsymbol{W}^{\prime} \boldsymbol{R}^{-1}\left(\mathbf{Y}^{*}-\boldsymbol{W} \boldsymbol{\theta}_{*}-\boldsymbol{e}_{*}\right)
$$

This system is solved using cholesky factorization from the sparse library in R by Davis (2006).

C is a sparse matrix (populated primarily with zeros) representing the model coefficient matrix:

$$
C=W^{\prime} R^{-1} W+\left[\begin{array}{cc}
B^{-1} & 0 \\
0 & G^{-1}
\end{array}\right]
$$

$\boldsymbol{\theta}_{*=}\left[\boldsymbol{\beta}_{*}^{\prime}, \boldsymbol{u}_{*}^{\prime}\right]$ and $\boldsymbol{e}_{*}$ are random draws from the multivariate normal distributions:

$$
\left[\begin{array}{c}
\boldsymbol{\beta}_{*} \\
\boldsymbol{u}_{*}
\end{array}\right] \sim \boldsymbol{N}\left(\left[\begin{array}{c}
\boldsymbol{\beta}_{\mathbf{0}} \\
\mathbf{0}
\end{array}\right]\left[\begin{array}{cc}
\boldsymbol{B} & \mathbf{0} \\
\mathbf{0} & \boldsymbol{G}
\end{array}\right]\right)
$$

And

$$
\boldsymbol{e}_{*} \sim N\left(\boldsymbol{W} \boldsymbol{\theta}_{*}, \boldsymbol{R}\right)
$$


A realization from the required probability distribution $P\left(\boldsymbol{\theta} \mid \mathbf{Y}^{*}, \boldsymbol{W}, \boldsymbol{R}, \boldsymbol{G}\right)$ is then $\widetilde{\boldsymbol{\theta}}+\boldsymbol{\theta}_{*}$

\subsubsection{Updating the variance structures $G$ and $R$}

All information for the estimation of the residual structure $\mathbf{R}$ comes from the inverse-Wishart prior distribution, following a conditional sampling strategy provided by Korsgaard et al. (1999). For the G structure, the sum of squares matrix associated with each of the three random components has the form:

$$
S=\phi^{\prime} \boldsymbol{A}^{-1} \phi
$$

Where $\phi$ is a matrix of random effects with each row indexing the relevant row/column of $\mathbf{A}$, and each column indexing the relevant row/column in $\mathbf{V}$, and also $\mathbf{A}$ and $\mathbf{V}$ defined as in equations (9) and (10). The parameter (co)variance matrix is then sampled from the inverse-Wishart distribution:

$$
\boldsymbol{V} \sim \boldsymbol{I} \boldsymbol{W}\left(\left(\boldsymbol{S}_{\boldsymbol{p}}+\boldsymbol{S}\right)^{-1}, n_{p}+n\right)
$$

Where $\boldsymbol{S}_{p}$ and $n_{p}$ are the prior sum of squares and prior degrees of freedom, respectively, and $\mathrm{n}$ is the number of rows in the matrix of random effects $\phi$.

\subsubsection{Updating the cutoff points}

The methods developed by Cowles (1996), are used to allow the cutoff points to be updated simultaneously with the latent propensities of earning and medical care spending, using a Hastings-with-Gibbs update.

\subsection{The Data}

This analysis uses the pooled cross-sectional panel data of the 2015-2016-2017 US National Health Interview Surveys (NHIS) (Niankara, 2018c). First initiated in 1957 by the National Health Survey Act of 1956, the NHIS is a cross-sectional household, multistage probability sample survey conducted annually by the National Center for Health Statistics (NCHS) (Blackwell et al., 2014). The target population is the civilian non-institutionalized population 
residing in the USA at the time of the interview. Further details on its sampling design are found in the NCHS report (Parsons et al., 2014). The initial data in Niankara (2018c) contains 46,032 observations, 16,028 of which are from the 2015 sample, 16,369 from the 2016 sample, and the remaining 13,635 from the 2017 sample. From this sample of 46,032 respondents we extract the immigrants sub-sample with 6849 observations, distributed as 2741 (2015), 2225 (2016) and 1883 (2017), and further described in tables 1-4 below.

\section{Findings}

The results are divided into two parts; the first part provides the univariate and bivariate descriptive statistics, while the second part describes the econometric results from the Bayesian MCMC estimation of the BOP model.

\subsection{Descriptive results}

Focusing on the descriptive statistics for the variables of direct interest in this study as shown in table (1), we note that $40.02 \%$ of the adult immigrant respondents in the pooled sample come from the 2015 wave, $32.49 \%$ from the 2016 wave, and the remaining $27.49 \%$ from the 2017 wave. Of all immigrant respondents in the pooled sample, 63.9\% report speaking English very well, $23.3 \%$ report speaking well, while the remaining $12.8 \%$ report not speaking English well. Furthermore, the majority (37.2\%) report earning less than $\$ 35,000$, while $31.2 \%$ report earning between $\$ 35,000$ and $\$ 65,000$, and the remaining $31.6 \%$ report earning over $\$ 65,000$. With respect to family annual care spending, the greater majority of adult immigrant respondents (39.3\%) reports spending less than $\$ 500$ annually on medical care, followed by $33.2 \%$ reporting spending between $\$ 500$ and $\$ 2000$, while the remaining $27.4 \%$ reports spending over $\$ 2000$.

In table (2) the descriptive statistics for the socio-demographic qualitative control variables show in the last column that $53.2 \%$ of immigrant respondents in the pooled sample are males, while the remaining $46.8 \%$ are females. In addition, the racial distribution shows 
that over half $(55.9 \%)$ of immigrant respondents are Caucasians, followed by $32.4 \%$ Asians, then $10.3 \%$ Blacks, and the remaining $1.4 \%$ are of other races. Furthermore, the majority (72.6\%) are currently married, followed by $16.7 \%$ who have never married, and $10.7 \%$ who were previously married. Moreover, the greater majority of adult immigrant respondents (65.7\%) reports now being U.S. citizens, while the remaining $34.3 \%$ are still non-citizens. Finally, the regional distribution across the four census regions shows that the greatest majority of adult immigrants (35.6\%) live in southern states, followed by $34.9 \%$ living in western states, then $16.7 \%$ living in northwestern states, and finally $12.9 \%$ living in the Midwest region.

In the last column of table (3) $48.6 \%$ of adult immigrants respondents report having optional insurance to supplement their basic coverage, while the greater majority $(51.4 \%)$ reports lack coverage. Similarly, $23.4 \%$ report paying medical bills overtime, while the greater majority $(76.6 \%)$ reports not paying over time. Moreover, most $(81.9 \%)$ report not having a flexible spending account, while the remaining $18.1 \%$ report enrollment in such account before their employer. Finally, with respect to physical health conditions, the majority of adult immigrant respondents (36.9\%) reports an excellent health status, followed by $33.4 \%$ reporting a very good health status, then by $23.9 \%$ reporting a good health status, and finally $5.8 \%$ reporting a fair or poor health status.

In table (4), which presents the descriptive statistics for the quantitative control variables, we note that the mean time spent working per week has remained stable and over 40 hours/week between 2015 and 2017, with a pooled sample average of 41.42 hours, and a standard deviation of 11.14 hours. In addition, the mean age of adult immigrant respondents has remained stable around 44 years, with a pooled sample average of 44.29 years, and a standard deviation of 11.59 years. Furthermore, the average adult immigrant has over 15 years of education with a standard deviation of 3.85. Finally, the insurance premium figures suggest an increase in average premium costs from $\$ 3791$ (2015), to $\$ 4018$ (2016), and 
ending with $\$ 4112$ (2017); for a pooled sample average of $\$ 3973$, and a standard deviation of $\$ 3519$.

In order to understand the unconditional relationships between ELP, annual earnings and medical care spending, we also perform the chi-square test of independence between the three dimensions of immigrants integrations, with the results summarized in table (5). In fact, a statistically significant relationship is found between ELP and annual medical expenditures, between ELP and annual earnings, but also between annual earnings and medical expenditures. This is seen from the respective chi-squared test statistics in table (5), along with the p-values less than the 5\% significance level. As such, we proceed to summarize the unadjusted conditional distributions of the three dimensions of immigrants' integration in table (6).

\subsection{Econometric results}

The presentation of the econometric results is divided into three sub-sections; the first one focuses on describing the direct effects of ELP on immigrant families' annual earnings and medical care spending propensities, but also describes the nature of the relationship between the two outcome variables. The second sub-section focuses on describing the effects of the control variables on immigrant families' earnings propensity, while the last sub-section focuses on describing the effects of the control variables on immigrant families' medical care spending propensity.

For our MCMC estimation, we defined 100,000 iterations of the algorithm with a burnin period of 15,000 iterations, and a thinning interval of 10 iterations. This has led to an effective sample size of 8500 Markov draws, which were then used to estimate the parameters of the model, along with their $95 \%$ confidence intervals (CI). In addition to the fixed parameters described in equation (8), and the cutoff points described in section (3.2.5), the algorithm estimates the G-structure for the random effects as described in equation (9). Here it includes the observed sampling errors across census regions (south, northwest, Midwest, west), and the 
sampling errors across survey years $(2015,2016,2017)$ in the two measured outcomes (annual earnings and medical care spending). After accounting for these two sources of variations, all remaining variations in annual earnings and medical care spending are idiosyncratic, and described by the residual variance-covariance matrix ( $\mathbf{R}$-structure).

\subsubsection{Random effects, residuals and cutoff points estimates}

The results of the random effects variance $(G)$ are summarized in table (7), and show statistically significant posterior mean sampling errors across U.S. census regions of 1.71 (with 95\% CI [2.18e-17; 6.41]), and 7.82 (with 95\% CI [8.30e-06; 26.75]) for respectively annual medical care spending and annual earnings. Similarly, the estimated posterior mean sampling errors across survey years are found to be 0.11 (with 95\% CI [2.20e-17; 0.07]), and 21.56 (with 95\% CI [4.02e-17; 40.78]) for annual medical care spending and annual earnings, respectively.

The results of the estimated residual variance-covariance matrix $(\mathrm{R})$ is summarized in table (8). The table shows a variance of 403.72 (with 95\% CI [3.96; 851.94]) for immigrant families annual medical care spending, a variance of 474.22 (with 95\% CI [9.29; 1432.65]) for their annual earnings, and a positive and significant covariance value of 31.31 (with $95 \% \mathrm{CI}$ $[0.27 ; 84.57])$ between annual earnings and medical care spending. This later result suggests that as immigrant families' annual earnings increase, so do their annual medical care spending and vice versa. Using the estimated variances and covariance, we calculate the correlation coefficient between annual earnings and medical care spending to be $\tilde{\rho}=0.072$ or $[31.31 /(\sqrt{403.72} * \sqrt{474.22})]$. This result indicates a small yet statistically significant correlation between immigrant families' annual earnings and medical expenditures in the U.S.

\subsubsection{ELP effects on earnings and medical care spending propensities}

The results of ELP on immigrant families' annual earnings suggest that limited ELP has a consistently negative and increasing effect on families' propensity to earn income. In fact, 
among the immigrants that reports speaking English very well, a one level decrease in ELP is found to reduce average annual earnings propensity by $\$ 44.83$ (with $95 \%$ confidence interval [-\$90.32; $-\$ 7.35]$ ). This figure rises to $\$ 50.66$ (with 95\% CI [-\$102.20; $-\$ 8.73]$ ) among the immigrants that report speaking English well, and increases further to \$56.97 (with 95\% CI [\$114.56; -\$9.95]) among the immigrants that reports not speaking English well. These results seem to indicate an approximate average premium of $\$ 6$, for each level of immigrants' ELP in post-ACA-USA.

The results of ELP on immigrant families' annual medical care spending also suggest that limited ELP has a consistently positive effect on families' propensity to spend on medical care. In fact, among the immigrants that reports speaking English very well, a one level decrease in ELP is found to increase average annual propensity to spend on medical care by $\$ 8.09$ (with 95\% CI [\$0.73; \$16.49]). This figure is however reduced to $\$ 6.09$ (with 95\% CI [ $\$ 0.14$; \$13.41]) among the immigrants that report speaking English well, and decreases further to $\$ 4.32$ (with 95\% CI [-\$0.71; \$11.04]), among the immigrants that report not speaking English well.

\subsubsection{Control variables effects on immigrant families earnings propensity}

The effects of the socio-demographic qualitative control variables on immigrant families' annual earnings show that families with adult female respondents have lower earnings propensity -10.94 (with 95\% CI [-21.99; -1.91]) compared to those with adult male respondents. Similarly, compared to families with a white adult respondent, those with black adult respondents have lower earnings propensity -2.19 (with 95\% CI $[-5.89 ;-0.06]$ ), while those with Asian adult respondents have higher earnings propensity 5.33 (with 95\% CI [0.84; 10.95]). In addition, compared to immigrant families with currently married adults' respondents, those with never married respondents have lower earnings propensity -3.81 (with 95\% CI [-8.31; 0.47]). Furthermore, compared to immigrant families with adults respondents having extended 
health insurance coverage, the families lacking such coverage have lower earnings propensity -4.43 (with $95 \%$ CI [-9.19; -0.68 ]). Similarly, compared to families with adult respondents paying medical bills over time, those who do not pay overtime have higher earnings propensity of 5.35 (with 95\% CI $[0.83 ; 11.06]$ ). In addition, families with adult respondent lacking a flexible spending account have a lower earnings propensity,-6.84 (with 95\% CI [-13.96; -1.10]), compared to families who use a flexible spending account.

With respect to physical health status, compared to families with adult respondents reporting an excellent health condition, families reporting any other health status have a lower annual earnings propensity. In fact, these figures are -0.22 (with 95\% CI [-2.01; 1.34]) for those reporting a very good health status, -2.61 (with 95\% CI $[-6.09 ;-0.25]$ ) for those reporting a good health status, -2.78 (with $95 \%$ CI $[-7.43 ;-0.21]$ ) for those reporting a fair or poor health status.

The effects of the quantitative control variables show that a one hour increase in weekly labor supply by the adult respondent significantly increases immigrant families earnings propensity by $\$ 0.60$ (with $95 \%$ CI [ $\$ 0.10 ; \$ 1.20]$ ). Similarly, a one-year increase in adult respondent's age significantly increases earnings propensity by $\$ 0.16$ (with $95 \%$ CI [ $\$ 0.02$; \$0.34]). Moreover, each level increase in adult respondents' education increases earnings by $\$ 1.94$ (with 95\% CI [\$0.34; \$3.89]). Finally, every dollar spent on health insurance premium by the adult respondent increases earnings propensity by $\$ 0.07$ (with $95 \%$ CI $[\$ 0.01 ; \$ 0.15]$ ).

\subsubsection{Control variables effects on the propensity to spend on medical care}

The effects of the socio-demographic qualitative control variables on immigrant families' propensity to spend on medical care show that families with adult female respondents have a spending propensity that is 1.27 greater (with 95\% CI $[0.03 ; 2.98]$ ) than those with adult male respondents. Moreover, families with black adult respondents and those with Asian adult 
respondents have lower propensities of - 3.78 (with 95\% CI [-7.11; -0.40]), and -1.91 (with 95\% CI $[-3.92 ;-0.13])$ to spend on medical care when compared to white respondents.

In addition, compared to immigrant families with currently married adults', those previously married and those never married have lower propensities of spending on health care of -5.53 (with 95\% CI [-10.02; -0.62]) and -4.66 (with 95\% CI [-8.45; -0.57]), respectively. Furthermore, compared to immigrant families with extended health insurance coverage, the families with who lack coverage have lower medical care spending propensity of -1.82 (with 95\% CI $[-3.75 ;-0.15])$. Similarly, compared to families with adult respondents paying off medical bills over time, those with adults not doing so have lower medical care spending propensity of -13.90 (with $95 \%$ CI $[-23.30 ;-2.40]$ ). In addition, families who report having no flexible spending account have a lower medical care spending propensity of -5.73 (with $95 \%$ CI [-9.94; -0.67]), compared to families who have a flexible spending account.

With respect to physical health status, families with adult respondents reporting any other physical health status have higher medical care spending propensity compared to respondents reporting an excellent health condition. In fact, these figures are 1.70 (with 95\% CI $[0.08 ; 3.69])$ for those reporting a very good health status, 3.96 (with 95\% CI $[0.41 ; 7.21]$ ) for those reporting a good health status, and 7.72 (with 95\% CI [0.86; 13.83]) for those reporting a fair or poor health status.

The effects of the quantitative control variables show that a one-year increase in an adult respondent's age significantly increases medical care spending propensity by $\$ 0.12$ (with $95 \%$ CI [\$0.01; \$0.23]). Moreover, each level increase in adult respondents' education increases medical care spending propensity by $\$ 0.26$ (with $95 \%$ CI [ $\$ 0.02 ; \$ 0.52]$ ). Furthermore, every dollar spent on health insurance premium by an adult respondent increases medical carespending propensity by $\$ 0.10$ (with $95 \%$ CI $[\$ 0.01 ; \$ 0.17]$ ). Finally, the cutoff points results 
for the ordered response variables show a posterior mean value of $\delta_{2}=20.57$ (with $95 \%$ CI [3.79; 41.46]) for annual earnings, and $\mu_{2}=17.67$ (with 95\% CI [2.24; 28.57]) for annual medical care spending.

\section{Discussions of the results}

Given the multiple ways in which health insurance can enhance the economic and social well-being of immigrants and their families, and given that immigrants and their children are less likely to have health insurance, addressing issues of immigrants' health care market integration is of the outmost importance, and complementary to their economic integration.

In 2004, prior to the ACA, the United States spent around $\$ 1.9$ trillion, or $16 \%$ of its gross domestic product (GDP) on health care; this averages to about $\$ 6,280$ for each man, woman, and child (Stanton and Rutherford, 2006). By 2012, health spending reached $\$ 2.8$ trillion, or $\$ 8915$ per person, and accounted for $17.2 \%$ of gross domestic product (Jaffe and Frieden, 2014). After the ACA took effect however, Chua and Sommers (2014) showed that the dependent coverage provision improved protection against medical costs (a 3.7 percentage points reduction in out-of-pocket expenditure) among adults aged 19 to 25 years compared with older adults relatively unaffected by the law. Furthermore, Allison (2017) reported a reduction in the odds of out-of-pocket and total expenditures exceeding zero for the elderly and near elderly (60 to 70) enrolled in Medicare. This improvement has also been felt in the U.S. immigrant population, which recorded disproportionate gains in health insurance coverage under ACA. About 5.9 million more nonelderly immigrant adults and 1.9 million more children of immigrants accessed health coverage in 2015, compared to the figures in 2010.

Our findings show that limited English language proficiency leads to higher propensities of medical care spending in the U.S. immigrant population. If true, then policies that improve immigrants ELP in the USA would have significant implications for immigrants contribution to national health care spending as well as economic prosperity. In fact, in light of our results, 
improved immigrants' ELP should contribute to reducing the per capita national medical expenditure of $\$ 10,500$ reported by Phelps (2017) for the 325 million people living in the U.S. as of 2016. In addition, improved ELP along with better health care coverage would improve well-being for immigrants and their children. The latter group, by accounting for about one in four $(24 \%)$ of all children under 18 years old in the U.S., will play an important role in the future workforce. As such, keeping them (and their parents) healthy so they are better able to reach their full potential, and strengthen the U.S. economy for the coming decades will be more of a strategic investment worth consideration.

Furthermore, this study also revealed that limited E proficiency reduced immigrant families' annual earnings propensity in post-ACA-USA. Given the potential adverse health care market effect of limited ELP as discussed above, and the interdependence between the U.S. health care market and labor market (Niankara, 2018b), this result is not so surprising. Since labor supply and earnings depend on health capital (Grossman, 1972), adverse health outcomes due to limited ELP can but reduce labor supply, and earnings (Chiswick and Miller, 2017). Authors are divided on ACA effects on U.S. labor market, some suggest an adverse effect on labor supply (Colman and Dave, 2018; Depew, 2015), others report no substantial change (Heim et al., 2015; Schoen, 2016), while others further report inconclusive effects (Gaudette et al., 2016). Our latter result suggests however that improving ELP for immigrants' families would not only have a direct effect on immigrants' labor supply and earnings potential in post-ACA-USA, but also have an indirect effect through better health care market outcomes.

Although this study is the first to investigate the joint effects of English language proficiency on health care market and the labor market outcomes, the results are consistent with those examining the issues separately. Indeed the statistically positive and significant correlation coefficient between immigrants families' annual earnings and medical care spending, suggests that jointly modelling the two processes adds value to our overall 
understanding of the relationships between the various dimensions of immigrants integration in the USA.

Furthermore, our finding that limited ELP adversely affects immigrants' health care market integration through increased medical care spending propensity is supported by others. For instance, Gonzalez et al. (2010) showed that U.S. immigrants with limited ELP tend to have poorer understanding of their illness, and lack understanding of the treatment that they receive. Similarly Clark et al. (2004) showed that immigrants with limited ELP are less likely to follow treatment instructions and physician's recommendations or to pay follow-up visits. In addition, Divi et al. (2007) also showed that they have difficulty accurately expressing their symptoms, inhibiting physicians' ability to accurately diagnose. All of these contribute to unnecessary diagnostic testing and hospital admissions (Lopez et al., 2015) and thereby to increased unnecessary medical care spending.

Finally, our finding that limited ELP adversely affects immigrants' labor market integration through reduced earnings propensity is also supported by the past literature. Indeed Chiswick and Miller (2015) shows that immigrants tend to have weaker economic position at arrival because of low ELP. A result initially reported by Miranda and Zhu (2013), and further confirmed by Schuss (2018). This is mostly so, because increased ELP helps immigrants access information and social contacts, allowing them to build more cultural knowledge, and thereby adjust more easily to the labor market in the United States.

\section{Conclusions}

In this paper, we have analyzed the effects of self-reported English language proficiency on U.S. immigrant families' annual earnings and medical care spending. Using data from the U.S. National Health Interview Surveys (NHIS), we explored the relative importance of linguistic integration on immigrants' health and economic integration in receiving host 
countries. Given the cross-sectional multi-stage probabilistic sampling design of the NHIS and the qualitative ordinal nature of our three interrelated dimensions of immigrant integration (English Language Proficiency, Annual Earnings, Annual Medical Care Spending), we relied on a mixed bivariate ordered probit modeling with Bayesian Markov Chain Monte Carlo estimation.

Our analysis produces several interesting results with significant implications for immigration and health care policy reform in the U.S. The findings are 1) Among immigrants, increased ELP improves earnings propensity in post-ACA-USA. 2) As Among immigrants, increased ELP reduces medical care spending propensity in post-ACA-USA. 3) There is a significant positive correlation between immigrants' families' annual earnings and medical care spending in post-ACA-USA. We conclude therefore that overall, the evidence from the pooled cross-sectional sample data of the last three waves of the NHIS is not enough to reject any of our three formulated hypotheses. Therefore we conclude that efforts to improve immigrants' ELP in the U.S. would lead to greater integration into U.S. society and labor force leading to greater earnings as it leads to relatively greater spending on health care by the immigrant families, themselves. One implication of this is that public assistance to fund health care of immigrants may eventually fall as immigrants earn more and better integrate into the greater U.S. society.

\section{Disclosure of Funding}

This research did not receive any specific grant from funding agencies in the public, commercial, or not-for-profit sectors.

\section{Declaration of interest}

None 


\section{$\underline{\text { Reference list }}$}

Allison, John R (2017), The Affordable Care Act and Prescription Drug Expenditures: A Comparison of the Near Elderly and Elderly, PhD thesis, Georgetown University.

Andreae, M. H., White, R. S., Chen, K. Y., Nair, S., Hall, C., \& Shaparin, N. (2016). The effect of initiatives to overcome language barriers and improve attendance: a cross-sectional analysis of adherence in an inner city chronic pain clinic. Pain Medicine, 18(2), 265-274.

Angrist, J. D., Imbens, G. W., \& Rubin, D. B. (1996). Identification of causal effects using instrumental variables. Journal of the American statistical Association, 91(434), 444-455.

Batalova J. \& Alperin E. (2018). Immigrants in the U.S. States with the Fastest-Growing ForeignBorn Populations. Washington, DC: Migration Policy Institute. (accessed 10 September 2018) https://www.migrationpolicy.org/article/immigrants-us-states-fastest-growing-foreign-bornpopulations

Batalova, J., Fix M., \& Greenberg, M. (2018). Chilling Effects: The Expected Public Charge Rule and its Impact on Legal Immigrant Families' Public Benefits Use. Washington, DC: Migration $\begin{array}{lllll}\text { Policy Institute. } & \text { (accessed } & \text { 2018) }\end{array}$ https://www.migrationpolicy.org/research/chilling-effects-expected-public-charge-ruleimpact-legal-immigrant-families

Bates, T. (1994). Social resources generated by group support networks may not be beneficial to Asian immigrant-owned small businesses. Social Forces, 72(3), 671-689.

Becker, G. S. (1962). Investment in human capital: A theoretical analysis. Journal of political economy, 70(5, Part 2), 9-49.

Bishop, J. (1994). The impact of previous training on productivity and wages. In L. M. Lynch (Ed.), Training and the private sector (pp. 161 - 200). Chicago: University of Chicago Press.

Blanas, D. A., Nichols, K., Bekele, M., Lugg, A., Kerani, R. P., \& Horowitz, C. R. (2013). HIV/AIDS among African-born residents in the United States. Journal of Immigrant and Minority Health, 15(4), 718-724.

Bleakley, H., and Chin, A. 2010. "Age at Arrival, English Proficiency, and Social Assimilation Among US Immigrants.” American Economic Review: Applied Economics 2 (1): 165-192

Borjas, G. J. (2005). The labor market impact of high-skill immigration. American Economic Review, 95(2), 56-60.

Borjas, G. J. (2007). Mexican immigration to the United States. Chicago: University of Chicago Press.

Bound, J., Jaeger, D. A., \& Baker, R. M. (1995). Problems with instrumental variables estimation when the correlation between the instruments and the endogenous explanatory variable is weak. Journal of the American statistical association, 90(430), 443-450.

Bousmah, I., Grenier, G., \& Gray, D. (2018). Linguistic Distance, Languages of Work and Wages of Immigrants in Montreal (No. 1805E). (accessed 12 spetember 2018) from https://socialsciences.uottawa.ca/economics/sites/socialsciences.uottawa.ca.economics/files/18 05e.pdf 
Browne, W. J., \& Draper, D. (2006). A comparison of Bayesian and likelihood-based methods for fitting multilevel models. Bayesian analysis, 1(3), 473-514.

Brunello, G., M. Fort, N. Schneeweis \& R. Winter-Ebmer (2016) The causal effect of education on health: what is the role of health behaviors? Health Economics, 25, 314-336.

Budria, S., and P. Swedberg. 2015. "The Impact of Language Proficiency on Immigrants Earnings." Revista de Economa Aplicada 67: 63-91.

Calo, W. A., Cubillos, L., Breen, J., Hall, M., Rojas, K. F., Mooneyham, R., \& Garcia, N. (2015). Experiences of Latinos with limited English proficiency with patient registration systems and their interactions with clinic front office staff: an exploratory study to inform community-based translational research in North Carolina. BMC health services research, 15(1), 570.

Camarota, S. A. (2012). Immigrants in the United States: A profile of America's foreign-born population. Washington, DC: Center for Immigration Studies. (accessed 9 september 2018) from https://cis.org/Immigrants-United-States-2010

Camarota, S. A., \& Zeigler, K. (2016). Immigrants in the United States: A profile of the foreign-born using 2014 and 2015 Census Bureau data. Washington DC: Center for Immigration Studies. (accessed 9 September 2018) from https://cis.org/sites/cis.org/files/immigrant-profile_0.pdf

Capps, R., Bachmeier, J. D., Fix, M., \& Van Hook, J. (2013). A demographic, socioeconomic, and health coverage profile of unauthorized immigrants in the United States. Washington, DC: Migration Policy Institute. (accessed $10 \quad$ September 2018) from http://lawprofessors.typepad.com/files/cirbrief-profile-unauthorized-1.pdf

Carten, M. L., Castillo-Mancilla, J. R., Allshouse, A. A., \& Johnson, S. C. (2013). Characteristics of foreign-born HIV infected individuals and differences by region of origin and gender. Journal of Immigrant and Minority Health, 15(4), 667-672.

Castañeda, H., Holmes, S. M., Madrigal, D. S., Young, M. E. D., Beyeler, N., \& Quesada, J. (2015). Immigration as a social determinant of health. Annual review of public health, 36, 375-392.

Cheng, E. M., Chen, A., \& Cunningham, W. (2007). Primary language and receipt of recommended health care among hispanics in the united states. Journal of General Internal Medicine, 22(SUPPL. 2), 283-288. doi:10.1007/s11606-007-0346-6

Chiswick, B. R. \& P. W. Miller (2010) Occupational language requirements and the value of English in the U.S. labor market. Journal of Population Economics, 23, 353-372.

Chiswick, B. R. \& P. W. Miller (2015) Chap 5 International migration and the economics of language. Handbook of the Economics of International Migration, vol.1, pp. 211-269.

Chua, Kao-Ping and Benjamin D Sommers (2014), 'Changes in health and medical spending among young adults under health reform', Jama 311(23), 2437-2439.

Chung, I. (2012). Sociocultural study of immigrant suicide-attempters: An ecological perspective. Journal of Social Work, 12(6), 614-629.

Clark, T., B. Sleath \& R. H. Rubin (2004) Influence of ethnicity and language concordance on physician-patient agreement about recommended changes in patient health behavior. Patient Education and Counseling, 53, 87-93.

Clarke, A., \& Isphording, I. E. (2017). Language barriers and immigrant health. Health Economics (United Kingdom), 26(6), 765-778. doi:10.1002/hec.3358 
Colman, Gregory and Dhaval Dave (2018), 'It's about time: effects of the affordable care act dependent coverage mandate on time use', Contemporary Economic Policy 36(1), 44-58.

Cowles, M. K. (1996). Accelerating Monte Carlo Markov chain convergence for cumulative-link generalized linear models. Statistics and Computing, 6(2), 101-111.

Current Population Survey (2015). Annual social and economic supplement. Washington DC: U.S. Census Bureau. (accessed 10 September 2018) from https://www2.census.gov/programssurveys/cps/techdocs/cpsmarl4R.pdf

Davis, A. T. (2006) Direct Methods for Sparse Linear Systems, SIAM Series "Fundamentals of Algorithms". Depew, Briggs (2015), "The effect of state dependent mandate laws on the labor supply decisions of young adults', Journal of health economics 39, 123-134.

Dillender, M. (2017). English skills and the health insurance coverage of immigrants. American Journal of Health Economics, 3(3), 312-345. doi:10.1162/ajhe_a_00077

Divi, C., Koss, R. G., Schmaltz, S. P., \& Loeb, J. M. (2007). Language proficiency and adverse events in U.S. hospitals: A pilot study. International Journal for Quality in Health Care, 19(2), 60-67. doi:10.1093/intqhc/mzl069

Duman Y. (2018) Integration of immigrants and the theory of recognition: "just integration", Ethnic and Racial Studies, 41(13), 2363-2365.

Duncan, A. \& A. Mavisakalyan (2015) Russian language skills and employment in the Former Soviet Union. Economics of Transition, 23(3), 625-656.

Elsayed, A., \& De Grip, A. (2018). Terrorism and the integration of Muslim immigrants. Journal of Population Economics, 31(1), 45-67.

Fernandez, A., D. Schillinger, E. M. Warton, N. Adler, H. H. Moffet, Y. Schenker, M. V. Salgado, A. Ahmed \& A. J. Karter (2011) Language barriers, physician-patient language concordance, and glycemic control among insured Latinos with diabetes: the Diabetes Study of Northern California (DISTANCE). Journal of General Internal Medicine, 26, 170-176.

Fryer, C. E., Mackintosh, S. F., Stanley, M. J., \& Crichton, J. (2013). I understand all the major things: How older people with limited english proficiency decide their need for a professional interpreter during health care after stroke. Ethnicity and Health, 18(6), 610-625. doi:10.1080/13557858.2013.828830

Funkhouser, E. (2000). Convergence in employment rates of immigrants. In G. J. Borjas (Ed.), Issues in the economics of immigration (pp. 143-184). Cambridge, MA: National Bureau of Economic Research.

Gaudette, E' tienne, Gwyn C Pauley and Julie Zissimopoulos (2016), 'Lifetime consequences of early and midlife access to health insurance: A review'.

Gee, G. C., \& Ponce, N. (2010). Associations between racial discrimination, limited english proficiency, and health-related quality of life among 6 asian ethnic groups in california. American Journal of Public Health, 100(5), 888-895. doi:10.2105/AJPH.2009.178012

Gelman, A., Carlin, J. B., Stern, H. H., Rubin, D. B., 2004. Bayesian Data Analysis. Chapman \& Hall, 2nd edition. 
Gentsch, K., \& Massey, D. S. (2011). Labor market outcomes for legal Mexican immigrants under the new regime of immigration enforcement. Social Science Quarterly, 92(3), 875-893.

González, H. M., W. A. Vega \& W. Tarraf (2010) Health care quality perceptions among foreign-born Latinos and the importance of speaking the same language. The Journal of the American Board of Family Medicine, 23, 745-752.

Gracia-Cortes, L. A., Sorensen, D., 2001. Alternative implementations of monte carlo em algorithms for likelihood inferences. Genetics Selection Evolution 33 (4), 443-452.

Grossman, M. (1972). On the concept of health capital and the demand for health. Journal of Political Economy, 80(2), 223-255.

Guven, C. \& A. Islam (2015) Age at migration, language proficiency, and socioeconomic outcomes: evidence from Australia. Demography, 52, 513-542.

Haario, H., Saksman, E., Tamminen, J., 2001. An adaptive metropolis algorithm. Bernoulli 7 (2), $223-$ 242.

Heim, Bradley, Ithai Lurie and Kosali Simon (2015), 'The impact of the affordable care act young adult provision on labor market outcomes: evidence from tax data', Tax Policy and Economy 29(1), $133-157$.

Hoffman, S., Higgins, J. A., Beckford-Jarrett, S. T., Augenbraun, M., Bylander, K. E., Mantell, J. E., \& Wilson, T. E. (2011). Contexts of risk and networks of protection: NYC West Indian immigrants' perceptions of migration and vulnerability to sexually transmitted diseases. Culture Health \& Sexuality, 13(5), 513-528.

Jacobs, E., Chen, A. H., Karliner, L. S., Agger-Gupta, N., \& Mutha, S. (2006). The need for more research on language barriers in health care: A proposed research agenda. Milbank Quarterly, 84(1), 111-133. doi:10.1111/j.1468-0009.2006.00440.x

Jaffe, Harold W and Thomas R Frieden (2014), 'Improving health in the usa: progress and challenges', The Lancet 384(9937), 3-5.

John-Baptiste, A., G. Naglie, G. Tomlinson, S. M. Alibhai, E. Etchells, A. Cheung, M. Kapral, W. L. Gold, H. Abrams \& M. Bacchus (2004) The effect of English language proficiency on length of stay and in-hospital mortality. Journal of General Internal Medicine, 19, 221-228.

Jurcik, T., Ahmed, R., Yakobov, E., Solopieieva-Jurcikova, I., \& Ryder, A. G. (2013). Understanding the role of the ethnic density effect: Issues of acculturation, discrimination and social support. Journal of Community Psychology, 41(6), 662-678.

Kandel, W. A. (2011). The U.S. Foreign-born population: Trends and selected characteristics. Washington, DC: Congressional Research Service. (accessed 9 september 2018) from http://www.fas.org/sgp/crs/misc/R41592.pdf

Kim, G., Worley, C. B., Allen, R. S., Vinson, L., Crowther, M. R., Parmelee, P., \& Chiriboga, D. A. (2011). Vulnerability of older latino and asian immigrants with limited english proficiency. Journal of the American Geriatrics Society, 59(7), 1246-1252.

Kogan, I., Shen, J., \& Siegert, M. (2018). What Makes a Satisfied Immigrant? Host-Country Characteristics and Immigrants' Life Satisfaction in Eighteen European Countries. Journal of Happiness Studies, 19(6), 1783-1809.

Korsgaard, I. R., Andersen, A. H., Soresen, D., 1999. A useful reparameterization to obtain samples from conditional inverse wishart distributions. Genetics Selection Evolution 31 (2), 177-181. 
Kossoudji, S. A. (1988). English language ability and the labor market opportunities of Hispanic and East Asian immigrant men. Journal of Labor Economics, 6(2), 205-228.

Lebrun, L. A. (2012) Effects of length of stay and language proficiency on health care experiences among immigrants in Canada and the United States. Social Science \& Medicine, 74, 1062-1072.

Lee, L-F. and Porter, RH. (1984) Switching regression models with imperfect sample separation information - with an application on cartel stability. Econometrica: Journal of the Econometric Society, Vol. 52, No 2, pp. 391-418.

Lee, L. F. (1992). On efficiency of methods of simulated moments and maximum simulated likelihood estimation of discrete response models. Econometric Theory, 8(4), 518-552.

Leung, P., Cheung, M., \& Tsui, V. (2012a). Asian Indians and depressive symptoms: Reframing mental health help-seeking behavior. International Social Work, 55(1), 53-70.

López, L., Rodriguez, F., Huerta, D., Soukup, J., \& Hicks, L. (2015). Use of interpreters by physicians for hospitalized limited english proficient patients and its impact on patient outcomes. Journal of General Internal Medicine, 30(6), 783-789. doi:10.1007/s11606-015-3213-x

McCulloch, C.E. and Searle, S.R. (2001) Generalized Linear, and Mixed Models, John Wiley \& Sons, Ltd, New York.

McKelvey, R. D., \& Zavoina, W. (1975). A statistical model for the analysis of ordinal level dependent variables. Journal of mathematical sociology, 4(1), 103-120.

Miranda, A., and Y. Zhu. 2013. "English Deficiency and the Native Immigrant Wage Gap." Economics Letters 118 (1): 38-41

Mui, A. C., Kang, S. Y., Kang, D., \& Domanski, M. D. (2007). English language proficiency and healthrelated quality of life among chinese and korean immigrant elders. Health and Social Work, 32(2), 119-127. doi:10.1093/hsw/32.2.119

Nápoles, A. M., Santoyo-Olsson, J., Karliner, L. S., Gregorich, S. E., \& Pérez-Stable, E. J. (2015). Inaccurate language interpretation and its clinical significance in the medical encounters of Spanish-speaking Latinos. Medical care, 53(11), 940.

Niankara, I. (2016). "Modeling Health Insurance Enrollment Decisions in the U.S., Under Preferences Endogeneity: A Bayesian Multinomial Probit Approach", Journal of Global Business and Trade 12(2), 1-14.

Niankara, I. (2018a). Evaluating health consumers' preferences stability through joint estimation of revealed and stated health insurance preferences data. International Journal of Economics and Business Research, 15(2), 236-256.

Niankara, I. (2018b), "The relative influence of inter-generational co-residence on healthcare market and labor market outcomes in post affordable-care-act usa", Global Business and Economics Review, (Forthcoming) available online at http://www.inderscience.com/info/ingeneral/forthcoming.php?.jcode $=G B E R$

Niankara, I. (2018c), "Pooled Cross-sectional Sample Data of the 2015, 2016, 2017 National Health Interview Surveys for studying the determinants of Health care market and Labor Market Outcomes in Post Affordable Care Act USA", Data in Brief, 21, 1526-1532. https://doi.org/10.1016/j.dib.2018.10.130 
Ovaskainen, O., Rekola, H., Meyke, E., Arjas, E., 2008. Bayesian methods for analyzing movements in heterogeneous landscapes from mark-recapture data. Ecology 89 (2), 542-554.

Pfeffer, M. J., \& Parra, P. A. (2009). Strong ties, weak ties, and human capital: Latino immigrant employment outside the enclave. Rural Sociology, 74(2), 241-269.

Phelps, Charles E (2017), Health economics, Routledge.

Pierce S., Bolter J. and Selee A. (2018) U.S. Immigration Policy Under Trump: Deep Changes and Lasting Impacts. Washington, DC: Migration Policy Institute. (accessed 12 September 2018) From https://www.migrationpolicy.org/research/us-immigration-policy-trump-deep-changes-impacts

R Core Team (2015) R: A Language and Environment for Statistical Computing, R Foundation for Statistical Computing, Vienna, Austria [online] https://www.R-project.org/(accessed 10 October 2017).

Rudiger, A., \& Spencer, S. (2003). Social integration of migrants and ethnic minorities: policies to combat discrimination. In Conference on the Economic and Social Aspects of Immigration organized by the European Commission and OECD. (accessed 12 september 2018) from http://www.oecd.org/migration/mig/15516956.pdf

Sajaia, Z. (2008). Maximum likelihood estimation of a bivariate ordered probit model: implementation and Monte Carlo simulations. The Stata Journal, 4(2), 1-18.

Salinas, J. J., \& Sheffield, K. M. (2011). English language use, health and mortality in older mexican americans. Journal of Immigrant and Minority Health, 13(2), 232-238. doi:10.1007/s10903009-9273-4

Sanders, J. M., \& Nee, V. (1996). Immigrant self-employment: The family as social capital and the value of human capital. American Sociological Review, 61(2), 231-249.

Schachter, A., R. T. Kimbro \& B. K. Gorman (2012) Language Proficiency and Health Status: Are Bilingual Immigrants Healthier? Journal of Health and Social Behavior, 53, 124-145.

Shain, M. A. (2018). Shifting Tides: Radical-Right Populism and Immigration Policy in Europe and the United States. Washington, DC: Mirgration Policy Institute. (accessed 12 september 2018) from https://www.migrationpolicy.org/research/radical-right-immigration-europe-united-states

Shields, M. A., \& Price, S. W. (2002). The English language fluency and occupational success of ethnic minority immigrant men living in English metropolitan areas. Journal of Population Economics, 15(1), 137-160.

Schoen, Cathy (2016), The Affordable Care Act and the U.S. economy: A five-year perspective, Commonwealth Fund.

Schuss, E. (2018). The Impact of Language Skills on Immigrants' Labor Market Integration: A Brief Revision With a New Approach. The B.E. Journal of Economic Analysis \& Policy, [Online]. Retrieved 21 Sep. 2018, from doi:10.1515/bejeap-2017-0280

Schwei, R. J., Schroeder, M., Ejebe, I., Lor, M., Park, L., Xiong, P., \& Jacobs, E. A. (2018). Limited english proficient patients' perceptions of when interpreters are needed and how the decision to utilize interpreters is made. Health Communication, 33(12), 1503-1508. doi:10.1080/10410236.2017.1372047 
Sentell, T. \& K. L. Braun (2012) Low Health Literacy, Limited English Proficiency, and Health Status in Asians, Latinos, and Other Racial/Ethnic Groups in California. Journal of health Communication, 17, 82-99.

Squires, A., \& Jacobs, E. A. (2016). Language and communication issues impact healthcare providers around the world. International Journal of Nursing Studies, 54, 5-6. doi:10.1016/j.ijnurstu.2015.12.002

Stanton, Mark W and MK Rutherford (2006), The high concentration of U.S. health care expenditures, Agency for Healthcare Research and Quality Washington, DC.

The Lancet Public Health (2018). No public health without migrant health. The Lancet. Public health. 3(6), PE259 DOI: https://doi.org/10.1016/S2468-2667(18)30101-4

Terrazas, A. (2011). The economic integration of immigrants in the United States: Long- and short-term perspectives. Washington, DC: Migration Policy Institute. (accessed 8 september 2018) from http://www.migrationpolicy.org/pubs/economicintegration.pdf

Tegegne, M. A. (2018). Linguistic integration and immigrant health: The longitudinal effects of interethnic social capital. Journal of Health and Social Behavior, 59(2), 215-230. doi:10.1177/0022146518757198

Wilson, E., Chen, A. H., Grumbach, K., Wang, F., \& Fernandez, A. (2005). Effects of limited english proficiency and physician language on health care comprehension. Journal of General Internal Medicine, 20(9), 800-806. doi:10.1111/j.1525-1497.2005.0174.x

Xie, Y., \& Gough, M. (2011). Ethnic enclaves and the earnings of immigrants. Demography, 48(4), 1293-1315.

Xu, Q., \& Kalina, B. (2012). Service utilization for Latino children in mixed-status families. Social Work Research, 36(3), 209-221.

Zendedel, R., Schouten, B. C., van Weert, J. C. M., \& van den Putte, B. (2018). Informal interpreting in general practice: The migrant patient's voice. Ethnicity and Health, 23(2), 158-173. doi:10.1080/13557858.2016.1246939

Zhao, Y., Staudenmayer, J., Coull, B. A., \& Wand, M. P. (2006). General design Bayesian generalized linear mixed models. Statistical science, 21(1), 35-51. 